\title{
Chapter 11 \\ Critical Remote Sensing Contributions to Spatial Wildlife Ecological Knowledge and Management
}

\author{
Gregory J. McDermid, Nicholas C. Coops, Michael A. Wulder, \\ Steven E. Franklin, and Nicole E. Seitz
}

\begin{abstract}
Remote sensing has established a key role in modern wildlife ecology, but the data types and methods are both varied and complex, and the potential for misuse by the uninformed is high. The basic attributes of earth-observing sensors and data products can be described by their spectral, spatial, radiometric, and temporal resolutions, and general categories of data products are normally consistent across agencies and organizations. Users of remote sensing technology seeking to link information needs with remote sensing strategy must balance knowledge of data and processing techniques with a clear understanding of the nature of the information desired. Wielded within a sophisticated application framework, remote sensing allows for an impressive suite of wildlife ecology and habitat attributes to be modeled, predicted, and monitored through time, including land cover physiognomy, vegetation structure and condition, forage characteristics, specific nutrient concentrations, overall productivity, and biomass.
\end{abstract}

\subsection{Introduction}

A spatial information management approach to applied wildlife ecology will rely on our capacity to link animal-based data sets - observations related to a species' distribution, abundance, health, or genetics, for example - to a variety of spatially

\footnotetext{
G.J. McDermid $(\bowtie)$

Department of Geography, University of Calgary, Calgary, Alberta, Canada T2N 1N4

N.C. Coops

Department of Forest Resource Management, University of British Columbia, Vancouver, British Columbia, Canada V6T 1 Z4

M.A. Wulder

Canadian Forest Service (Pacific Forestry Centre), Natural Resources Canada, Victoria, British Columbia, Canada V8Z 1M5

S.E. Franklin

Department of Geography, Trent University, Peterborough, Ontario, Canada K9J 7B8

N.E. Seitz

Canadian Forest Service (Pacific Forestry Centre), Natural Resources Canada, Victoria, British Columbia, Canada V8Z 1M5
} 
explicit environmental variables. This idea is based on the general concept that an organism's characteristics and behaviors at both the individual and population levels are inextricably linked to the physical habitat in which it occurs (Guisan and Zimmermann 2000; Braun 2005). While the investigation of these links must be well-grounded by solid field observations, the multiple scales and extent over which information must be compiled suggests a key role for remote sensing instruments and related technologies. For example, it is becoming increasingly evident that the health of wild species is adversely affected by human activities and landscape change (e.g. Daszak et al. 2001; Farnsworth et al. 2005). Ongoing research may reveal a direct link between human-induced habitat changes and long-term physiological stress, leading to damaging health consequences in individual animals (i.e. impaired reproduction, diminished growth, suppressed immune function) and subsequent negative effects at the population level (i.e. low natality and survival rates, diminished abundance). An approach to understanding these relationships, based on sensitive and reliable measures of health, stress, and landscape change, is both urgently needed and impossible to conceive without remote sensing.

For decades, remote sensing has been acknowledged as a critical data source of environmental information, theoretically capable of supporting a broad range of ecological applications (Robinson 1985; Greegor 1986; Graetz 1990; Franklin 2001; Lewis 2003). The promise of the technology lies in its ability to deliver highquality, spatially explicit observations over large areas with regular revisit intervals, in a format that is both well-suited for ecological interpretation and readily integrated with data from other components of a modern spatial information management system (e.g., GPS, GIS modules). Recent reviews by Cohen and Goward (2004), Leimgruber et al. (2005), McDermid et al. (2005), and Gottschalk and Huettmann (2006), for example, document more than 30 years of success applying remote sensing technology to the analysis and modeling of wildlife-habitat relationships. However, as with all such multi-disciplinary partnerships, effectiveness can be hindered by miscommunication between the methods experts - practitioners of remote sensing, GIS, and other spatial technologies - and applications personnel with expertise in wildlife and ecology.

The linkages between ecologists and remote sensing scientists can be improved by addressing gaps in understanding through the establishment of widely accepted standards. As a data source and analysis tool, remote sensing is still relatively new, and its data are often not well known and improperly handled. However, in the few decades that the data have been available, solid synthesis applications have emerged. For example, land-cover and change-detection analyses are two instances of remote sensing products that have become widely accepted in the various user communities (Franklin and Wulder 2002; Wulder et al. 2003). Overall user satisfaction with these products can be partially attributed to an increased understanding of development strategies and characteristics, leading in turn to realistic user expectations surrounding results. However, remote sensing rarely replaces traditional field work. Instead, the technology represents a powerful suite of data sets and methodological procedures capable of complementing and extending ground observations 
accurately and efficiently over large geographic areas, and, as a result, provides an effective foundation for performing wildlife-ecological studies.

In this chapter, we explain the basic operation of remote sensing devices, and provide an overview of information products and major distribution centers. We then review the critical targets that remote sensing can address in support of wildlife research and modeling, with specific reference to key advancements and sample applications of interest to researchers in applied wildlife ecology. We conclude with the presentation of an application framework designed to link ecological information needs with the correct remote sensing imagery and information-extraction strategies in order to improve wildlife research and management.

\subsection{Remote Sensing Background}

For our purposes, remote sensing devices can be thought of as instruments, typically mounted on air- or space-borne platforms, which are designed to measure the electromagnetic radiation that is reflected and/or emitted by the surface of the Earth. For the most part, these earth-observing (EO) instruments are adapted to exploit portions of the electromagnetic spectrum that are not strongly impacted by the atmospheric gases and particles through which this radiation must pass. These atmospheric windows occur primarily in the visible, infrared, and microwave portions of the spectrum, and represent the wavelengths within which the vast majority of relevant sensors operate. Passive remote sensing devices rely primarily on the visible and infrared light provided by the sun, and constitute the familiar optical systems most commonly applied to wildlife studies. Active sensors such as lidar (light detection and ranging) and radar (radio detection and ranging) provide their own sources of illumination, and are increasingly employed in ecological work. Together, they represent a valuable emerging component of the discipline that is especially adept at difficult applications, such as characterizing the detailed vertical structure of vegetation (e.g., Hyde et al. 2006). Here we focus primarily on the use of passive EO instruments, a selection of which are presented in Table 11.1. To augment the background summary on remote sensing provided here, readers are advised to consider general text books by Campbell (2007), Richards and Jia (2006), and Lunetta and Elvidge (1998). We do not provide information on the aerial photography aspects of remote sensing, which have been reviewed in a related context elsewhere (Hall 2003).

Lefsky and Cohen (2003) review the background and considerations for the selection of remotely sensed data, describing in detail the various resolutions used to describe remote sensing systems: spatial, spectral, temporal, and radiometric. Gaining an understanding of these characteristics helps users select the data source that is best-suited to meet a given information need. Spatial resolution is the image characteristic that is typically of most interest to users. While the true concept is more nuanced, spatial resolution is often considered analogous to the pixel size of a digital image. A given image's pixel size indicates the instantaneous field of 
Table 11.1 Characteristics of low-, medium-, and high-spatial-resolution optical sensors (after Coops et al. 2006)

\begin{tabular}{|c|c|c|c|}
\hline Sensor & Footprint $(\mathrm{km} \times \mathrm{km})$ & $\begin{array}{l}\text { Spatial } \\
\text { resolution }^{\mathrm{a}}(\mathrm{m})\end{array}$ & $\begin{array}{l}\text { Spectral } \\
\text { resolution (nm) }\end{array}$ \\
\hline \multicolumn{4}{|c|}{ Low spatial resolution sensors } \\
\hline NOAA 17 (AVHRR) & 2,940 & 1,100 & $500-1,250$ \\
\hline SPOT 4 (VGT) & 2,250 & 1,000 & $430-1,750$ \\
\hline Terra (MODIS) & 2,330 & 500 & $366-14,385$ \\
\hline \multicolumn{4}{|c|}{ Medium spatial resolution sensors } \\
\hline Landsat-5 (TM) & 185 & 30 & $450-2,350$ \\
\hline Landsat-7 (ETM+) & 185 & 30 (MS/SWIR); 15 (pan) & $450-2,350$ \\
\hline SPOT 2 (HRV) & 60 & 20 (MS); 10 (pan) & $500-890$ \\
\hline SPOT 4 (HRVIR) & 60 & 20 & $500-1,750$ \\
\hline SPOT 5 (HRG) & 60 & 10 (MS); 20 (SWIR) & $500-1,730$ \\
\hline IRS (RESOURCESAT-1) & 141 & 23.5 & $520-1,700$ \\
\hline Terra (ASTER) & 60 & 15 & $530-1,165$ \\
\hline EO-1 (HYPERION) & 37 & 30 & $433-2,350$ \\
\hline \multicolumn{4}{|c|}{ High spatial resolution sensors } \\
\hline Orbview-3 & 8 & 4 (MS); 1 (pan) & $450-900$ \\
\hline WorldView-1 & $17.6 \mathrm{~km}$ swath & $0.5($ pan $)$ & $450-900$ \\
\hline QuickBird-2 & 16.5 & 2.44 (MS); 0.8 (pan) & $450-900$ \\
\hline IKONOS & 13.8 & 4 (MS); 1 (pan) & $450-850$ \\
\hline
\end{tabular}

${ }^{a} M S$ multispectral, SWIR shortwave infrared, pan panchromatic

view of the sensor, or the surface area across which radiance measures have been generalized; $30 \times 30 \mathrm{~m}$ in the case of Landsat Thematic Mapper, for example. This generalization occurs for each spectral band that is acquired for a given image type, and different bands may have different spatial resolutions.

The extent of an image is also linked to the spatial resolution, through sensor optics and altitude, among other factors. Images with smaller pixels typically cover a smaller portion of the Earth's surface, while those with larger pixels generally cover larger areas.

The spectral resolution defines the specific electromagnetic wavelengths across which an individual instrument acquires measurements. Multispectral sensors commonly have a relatively modest number of bands (up to 20) placed at locations where vegetation reflectance or absorption features are known to be present, and that also coincide with clear atmospheric windows. Hyperspectral systems are characterized by having a large number (greater than 20) of near-contiguous narrow spectral bands. The quality of spectral resolution is established not by the number of bands of data collected, but rather by their width. Narrow spectral bands are better able to characterize detailed reflectance characteristics, without unnecessarily generalizing the response (Wulder et al. 2004).

Temporal resolution is the frequency at which a given location on the Earth's surface is imaged, or can be imaged. A high temporal resolution would indicate that a location is imaged frequently. The temporal extent of a remote sensing 
data source is an aspect for additional consideration in wildlife ecology studies, indicating the historical holdings and archives of a given sensor. Efforts to quantify changes in habitat through change detection, for example, require imagery that 'bookends' the targeted time interval, and can be limited by the temporal extent of the relevant data sets. Coops et al. (2006) provide insights regarding im age selection and processing options for monitoring ecological disturbance and change.

Radiometric resolution refers to the precision with which radiance measurement is possible from a given data type, as indicated by the range of digital numbers recorded for each pixel. Inevitably, users must consider the trade-offs between such characteristics as image extent, desired local detail, temporal revisit frequency, and spectral information when selecting imagery for a given application. The 'perfect' remote sensing data source does not exist.

\subsubsection{Remote Sensing Data Products and Sources}

A description of the technical details surrounding the processing of raw sensor measurements into useable information products is beyond the scope of this chapter; interested readers are referred instead to the general remote sensing text books cited previously for the basics on this topic. However, users of remote sensing technology seeking to acquire appropriate data products require (1) a basic understanding of the various outputs available, and (2) some general guidelines regarding image sources and data distribution centers.

While remote sensing outputs are typically sensor- and organization specific, the general categories tend to be consistent across agencies and organizations. The Committee on Earth Observation Satellites categorizes EO data products according to their level of processing (Table 11.2). Level 0 represents raw data, which are generally not suitable for use in applied wildlife ecological studies. Level 1 products, by contrast, have been radiometrically calibrated, are often geometrically registered, and represent the familiar unprocessed imagery that supports large numbers of contemporary wildlife initiatives. However, while L1 is certainly the most flexible and widely used brand of EO imagery, the data remain unrefined, and typically require significant investments in order to generate useable information layers. Less well-known to the wildlife community is the wealth of derived L2 and L3 products available from many sensors: biophysical and geophysical information attributes generated by science teams eager to add value to EO data for the benefit of researchers and managers in other fields. For example, the National Aeronautics and Space Administration's (NASA's) Earth Observing System of satellites support hundreds of L2 and L3 data products designed to contribute to the measurement and monitoring of our planet (Parkinson and Greenstone 2000). While the global focus of EOS data emphasizes spatial scales that are often too coarse for detailed wildlife research, regional studies would be well-advised to take advantage of these underutilized - and often free - sources of information. 
Table 11.2 Summary of standard remote sensing data products. Product levels are generally consistent across earth-observing agencies and organizations throughout the world

\begin{tabular}{|c|c|c|}
\hline Data product & Description & Example \\
\hline L0 & $\begin{array}{l}\text { Reconstructed but unprocessed } \\
\text { 'raw' data with all available } \\
\text { supplementary information } \\
\text { (ephemeris, calibration) appended }\end{array}$ & Landsat 7 LOR \\
\hline L1 & $\begin{array}{l}\text { Radiometrically corrected data } \\
\text { converted to units of absolute } \\
\text { radiance; often scaled to integers } \\
\text { (digital numbers) for storage } \\
\text { efficiency. Some L1 products have } \\
\text { also been corrected for systematic } \\
\text { geometric errors, and re-sampled to } \\
\text { a user-specified map projection }\end{array}$ & $\begin{array}{l}\text { Landsat } 7 \text { L1R (radiometrically } \\
\text { calibrated) and L1G } \\
\text { (radiometrically calibrated and } \\
\text { geolocated) data; MODIS L1A } \\
\text { (radiometrically calibrated) and } \\
\text { L1B (radiometrically calibrated } \\
\text { and geolocated) }\end{array}$ \\
\hline L2 & $\begin{array}{l}\text { Derived biophysical and geophysical } \\
\text { information products, distributed at } \\
\text { the same locations and resolutions } \\
\text { as the L1 source data }\end{array}$ & $\begin{array}{l}\text { MODIS Surface Reflectance, LAI, } \\
\text { Evapotranspiration, Land Cover, } \\
\text { Sea, Sea Ice Cover, Chlorophyll } \\
\text { Fluorescence, and Surface } \\
\text { Temperature products }\end{array}$ \\
\hline L3 & $\begin{array}{l}\text { Derived biophysical and geophysical } \\
\text { information products that have } \\
\text { been resampled in space and/ } \\
\text { or time, often for the purpose of } \\
\text { completeness and consistency. } \\
\text { Resampling may include aspects } \\
\text { organization of averaging and } \\
\text { compositing }\end{array}$ & $\begin{array}{l}\text { MODIS gridded land, ocean, and } \\
\text { atmosphere products. Polar grids } \\
\text { and climate modeling grids are } \\
\text { also provided to facilitate use by } \\
\text { those research communities }\end{array}$ \\
\hline
\end{tabular}

The strategy and cost of acquiring EO imagery and products depends primarily on the sensor and platform of interest. Sensors are managed by a wide range of corporate and government entities that operate under a variety of price structures and copyright arrangements. In general, public organizations such as NASA and the European Space Agency provide relatively low-priced outputs under generous copyright conditions, and archived image databases are often freely available to the public through various on-line geoportals. The International Center for Remote Sensing Education maintains a useful list of Internet clearinghouses and data distribution portals for satellite imagery at http://www.r-s-c-c.org. Of particular interest to ecologists is the recent release of the full 30-plus-year archive of the Landsat mission into the public domain (Woodcock et al. 2008), and available through the United States Geological Survey at http://landsat.usgs.gov.

Unlike the widely available low- and medium-spatial-resolution satellite sensors operated by government organizations, most high-spatial-resolution sensors are controlled by private corporations with more restrictive copyright policies and market-driven data prices. Complicating the issue of data availability in these cases (and in some medium-spatial-resolution systems as well) is the need to task the sensor in order to acquire imagery over a given area of interest. This obviously requires forethought and communication with the satellite operator. Projects seeking to purchase these types of data after the fact will often come away frustrated. Up-to-date 
information on pricing, availability, and tasking requirements is normally available from official sources on-line.

\subsection{Linking Information Needs with Remote Sensing Strategy}

The widespread availability of digital imagery and sophisticated software packages has greatly enhanced the accessibility of remote sensing technology in wildlife ecology studies. However, the data and processing strategies are both varied and complex, and, as a result, the potential for misuse by the uninformed is high. Chief among all concerns regarding the use of remote sensing data sources and processing strategies is the selection of the proper tools and techniques, and a subsequent correct interpretation of findings. The ecological literature contains multiple references to disappointing experiences with remote sensing data products (e.g. Plummer 2000; Thogmartin et al. 2004; Gottschalk and Huettmann 2006), and while some have asserted that the technology has failed to deliver consistently on its initial ecological promise, it seems clear that the larger issue revolves around a lack of solid understanding regarding the use of the remote sensing in an ecological setting (McDermid et al. 2005; Fassnacht et al. 2006). As with all technical collaborations, there is an on-going need for users and producers of remotely sensed information to seek common ground with respect to the capabilities of the tools, and the wildlife community would benefit substantially from the development and adoption of a methodological framework that links ecological information needs with appropriate remote sensing strategy.

The past decade has witnessed a tremendous increase in the number of publiclyaccessible imaging platforms designed to deliver data at ever-increasing spatial, spectral, radiometric, and temporal resolutions. In addition to the familiar optical systems, there are the newly emerging technologies of lidar and various types of radar. While these recent choices have greatly enhanced our ability to conduct ecological modeling and monitoring activities, they also present complex challenges surrounding the selection of appropriate data and processing techniques. However, since the characteristics of ecosystems are generally determined by the primary tropic level vegetation (Graetz 1990) - the discussion of information-extraction strategies for use in ecological studies must begin with a review of the remote sensing scene model, and how it relates to vegetation as a hierarchical, multi-scale phenomenon.

\subsection{Multi-Scale Vegetation Structure}

Complex systems theory describes the behavior of ecological systems characterized by a large number of components interacting in a non-linear fashion and exhibiting adaptive properties through time (Kay 1991; Hay et al. 2002). An important characteristic of these systems - or at least, our perception of them - is that they intuitively take on the form of a nested hierarchy, in which finer objects (leaves, branches, trees) are nested within broader ones (stands, forests, cover types). These ideas are 
important, since they help to define conceptual models that categorize vegetated landscapes amongst scale domains, and express the spatial dimensions at which selected information occurs. These considerations are the foundation of a variety of classification systems (e.g. Anderson et al. 1976; Woodcock and Harward 1992; Franklin and Woodcock 1997) that are designed to organize information hierarchically, and provide a helpful basis for linking ecological information with remote sensing data sources and appropriate information-extraction techniques.

\subsection{The Remote Sensing Scene Model}

Strahler et al. (1986) described the remote sensing model as one composed of three distinct elements: the sensor, the atmosphere, and the scene. The scene comprises the area of interest, which, in the context of a terrestrial ecology application, might consist of a forested landscape viewed at a specific scale. A model of this landscape can normally be constructed as a series of two- or three-dimensional objects distributed on a homogeneous background (Jupp et al. 1988, 1989). In real imagery, these objects would appear as groups of similar-looking pixels, and could take several different forms depending upon scale. For example, a conifer forest could be modeled at fine scales as a series of two-dimensional objects representing trees, shadows, and patches of understory, or, at a broader scale, as collections of structurally homogeneous forest stands. In these two cases, the groups of pixels in the imagery might appear similar, but they would represent markedly different ground objects.

One of the keys to understanding the nature of remote sensing imagery is to know the relationship between the objects of interest in the scene and the pixels in the image. Generally speaking, this relationship can be described as belonging to one of two distinct types: H-resolution or L-resolution (Strahler et al. 1986). The H-resolution case occurs when the pixels are smaller than the objects under investigation; in other words, when there are many pixels per object. L-resolution imagery, on the other hand, occurs when the pixels are larger than the objects, or there are many objects per pixel. This designation is important, since it neatly summarizes the physical relationship between pixels and objects: knowledge that can be exceptionally useful in selecting the appropriate image-processing techniques.

H-resolution imagery tends to display high amounts of local variability, and, as a result, contains large amounts of spatial information. In general, H-resolution scenes are best suited for classification; particularly strategies involving object-based approaches (e.g. Burnett and Blaschke 2003; Benz et al. 2004), texture variables (e.g. Cohen and Spies 1992; Franklin and McDermid 1993; Carr and de Miranda 1998), contextual decision rules (e.g. Gong and Howarth 1992; Groom et al. 1996; Sharma and Sarkar 1998), and other forms of spatial analysis (e.g. Atkinson and Lewis 2000; Csillag and Kabos 2002). By definition, classification involves the placement of pixels into distinct categories, and works best, therefore, on H-resolution entities that fit cleanly into information classes of interest defined at a specific scale.

L-resolution imagery, on the other hand, typically has low amounts of local variability, and, consequently, small quantities of spatial information. These scenes tend to be better-suited for a variety of sub-pixel analyses, such as mixture modeling (e.g. 
Hall et al. 1996; Atkinson et al. 1997; Heinz and Chang 2001), or empirical techniques that operate on a per-pixel basis and relate multi- or hyper-spectral response patterns to various intra-pixel properties (e.g. Michaelsen et al. 1994; Cohen et al. 2001, 2003). The selection of an inappropriate processing strategy - texture analysis in an L-resolution scene, for example, or per-pixel regression modeling in an H-resolution case - leads almost invariably to frustration to many users.

Since natural systems are comprised of a hierarchy of objects nested one inside another at different scales, a single image can be H-resolution with respect to some objects and L-resolution with respect to others. For example, Landsat imagery would be considered L-resolution with respect to tree objects, since a single $30 \mathrm{~m}$ pixel contains several individual tree crowns (top part of Fig. 11.1). However, at
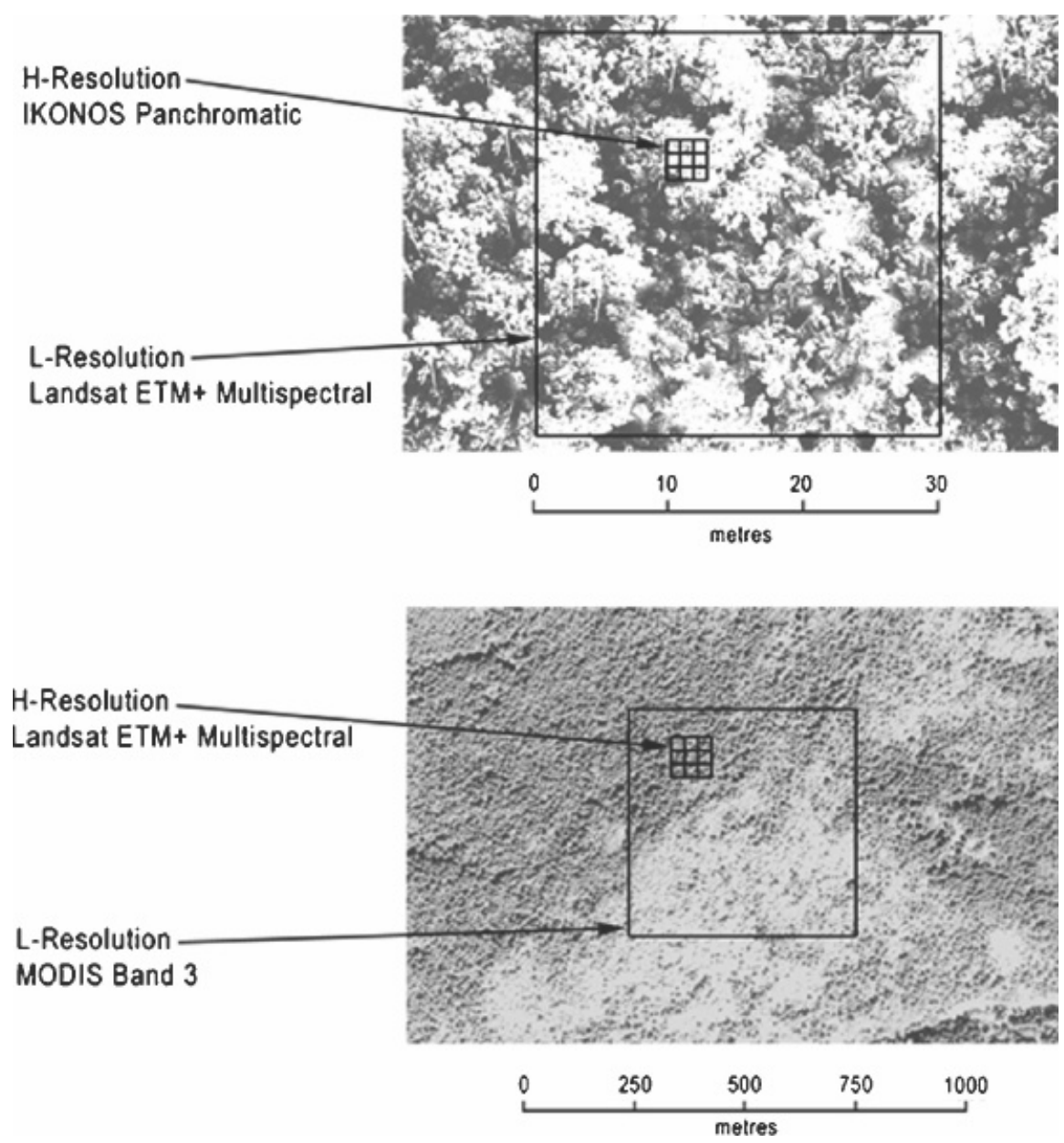

Fig. 11.1 Examples of H- and L-resolution imagery for a forested scene. At the tree level (top), Landsat ETM+ pixels are L-resolution, while IKONOS panchromatic pixels are $\mathrm{H}$-resolution. At the stand level (bottom) Landsat pixels are H-resolution, while visible-band MODIS pixels are L-resolution 
the stand scale, the same imagery would be considered H-resolution, since a 500ha forest stand can contain many different 30 m pixels (bottom part of Fig. 11.1). As a result, the correct information-extraction strategy is obtained not through blind devotion to a single image type or processing routine, but depends on a rather more sophisticated evaluation of (1) the scale of the information desired and (2) the spatial resolution of the imagery available.

\subsection{Critical Targets for Remote Sensing in Wildlife Ecology}

The diversity of remote sensing systems and their varying spectral, spatial, temporal, and radiometric resolutions allows for an impressive suite of wildlife ecology and habitat attributes to be modeled, predicted, and monitored through time. Principally, these attributes provide information on such factors as land cover physiognomy, vegetation structure and condition, forage characteristics, specific nutrient concentrations, overall productivity, and biomass. From these attributes, information on the distribution of shelter, shade, and nesting resources for wildlife, as well as potential to meet their metabolic needs, can be assessed. We surveyed the literature to investigate the role remote sensing has played in contemporary wildlife research (Table 11.3). In the following section, we highlight a number of the critical attributes that have been successfully predicted using remote sensing technology and have high relevance for wildlife ecology studies. Remote sensing of animals - another key remote sensing contribution to wildlife ecology - is reviewed elsewhere (Gillespie 2001; Ramanujan 2004; Majumdar et al. 2005).

\subsection{Land Cover, Condition, and Change}

A large number of key issues for wildlife management, including habitat suitability, land clearing and conversion to other land uses, and regional conservation planning, all require information on contemporary land cover condition and change. In most cases, remote sensing technology is used to predict land cover which is then used to infer spatially explicit habitat suitability for a wide range of wildlife species. One of the most common approaches to predicting land cover information from remotely sensed data is through the use of image classification, which involves the categorization of pixels a number of land cover classes, based on their similar spectral and/or spatial properties. When the user supervises this process by locating optimum examples of the land cover classes based on prior knowledge, field plots, or other information, the process is known as supervised classification (Richards and Jia 2006).

Cannon et al. (1982) was one of the first researchers to utilize Landsat MultiSpectral Scanner (MSS) (80 m spatial resolution) imagery in a wildlife context, using 1978 MSS data to classify shinnery oak rangelands in Western Oklahoma, US. A strong positive correlation was found between percentage of grassland 


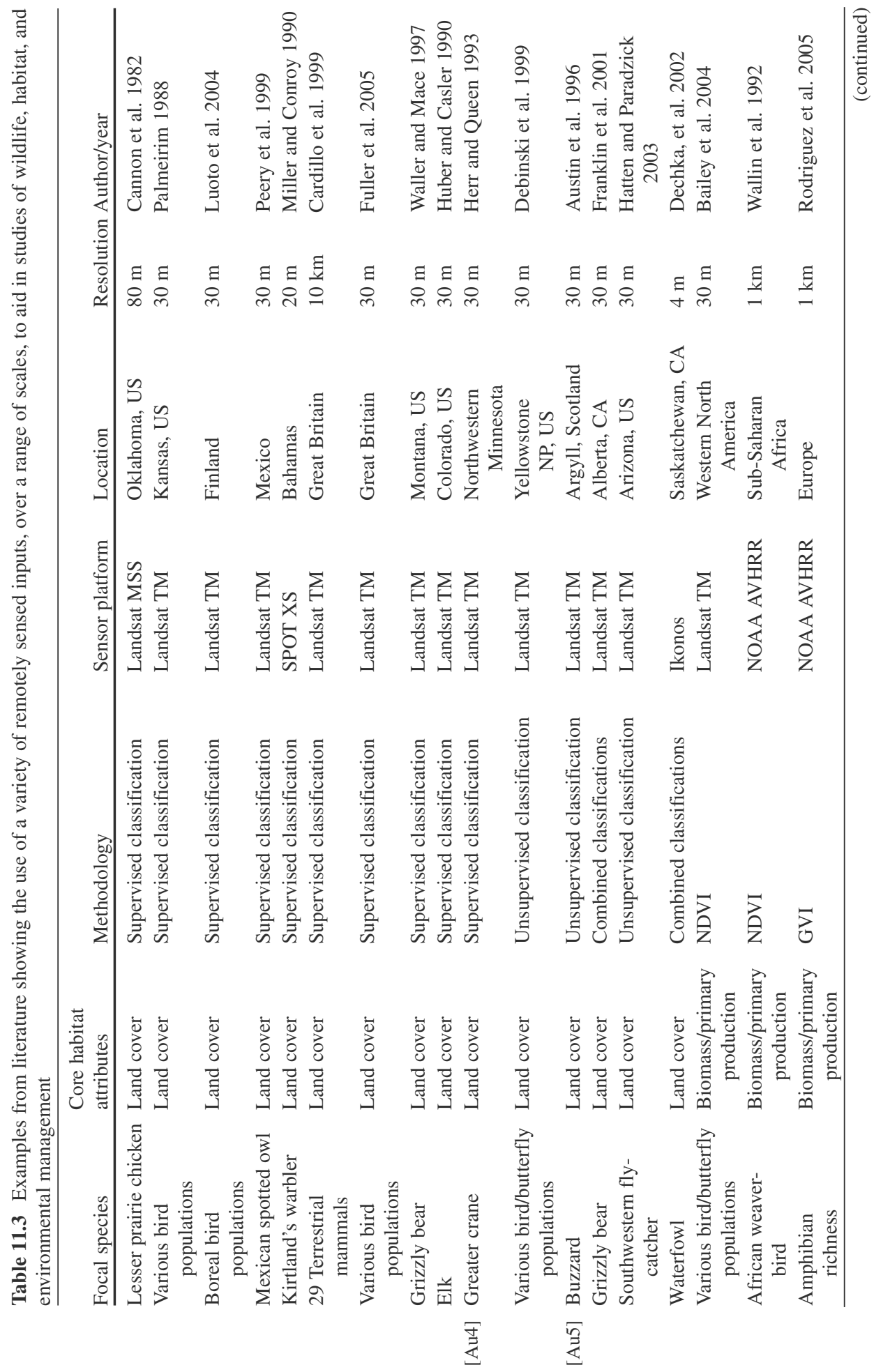




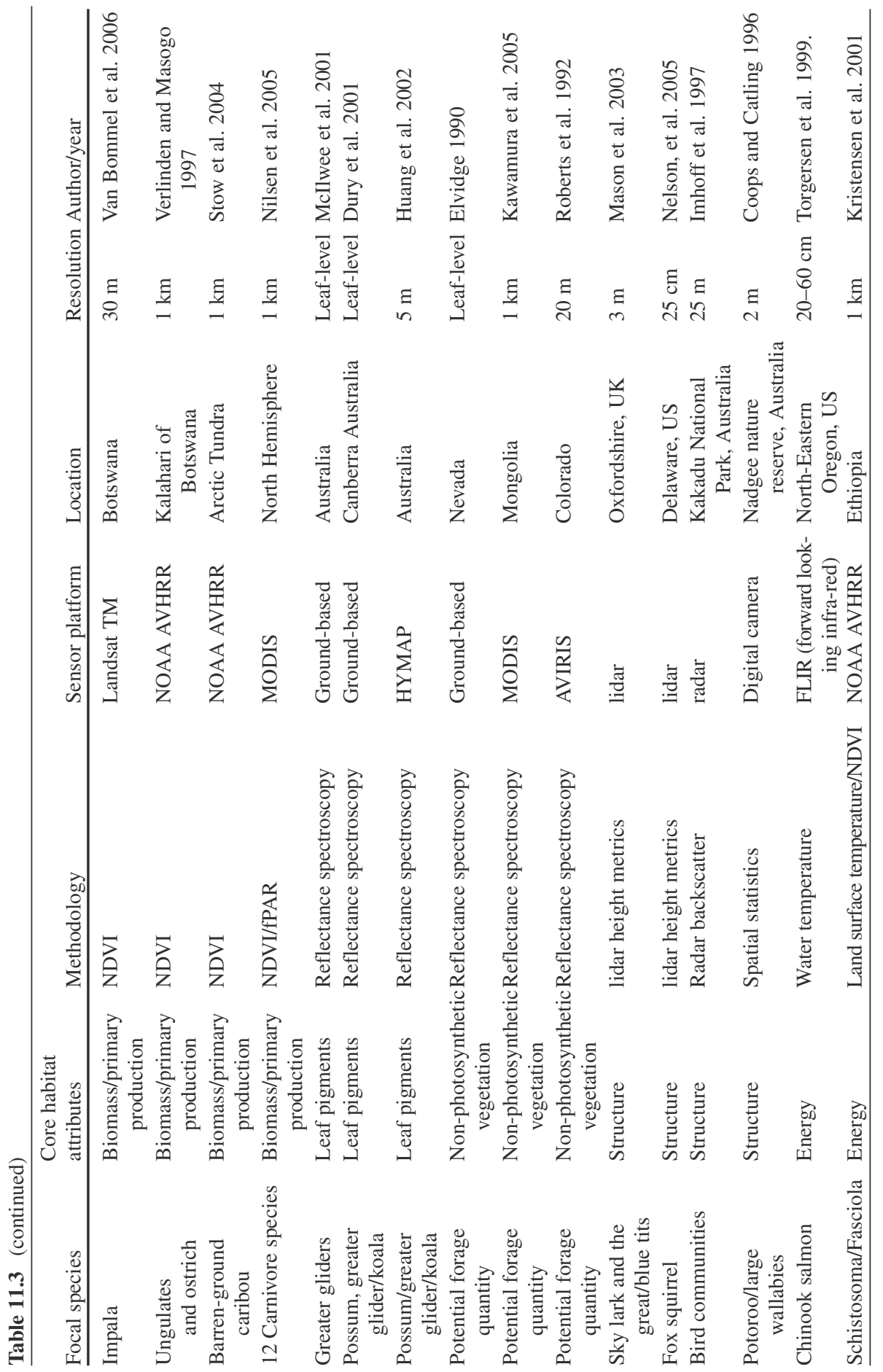


habitat and the population density of male lesser prairie chicken (Tympanuchus pallidicinctus). Even at this early adoptive stage, wildlife managers were encouraged to consider the use of timely satellite-based remote sensing observations as a cost-effective means of supplementing ground surveys. In a similar approach, Palmeirim (1988) undertook a supervised classification to generate a land cover map using Landsat Thematic Mapper (TM) imagery (30 m spatial resolution) to produce habitat suitability estimates for a number of avian species in northeastern Kansas. Seven land cover classes were predicted, and from this, patch statistics of different key land cover types such as the ratio of forest to grasses were calculated and related to different bird populations.

Also using Landsat TM data, Luoto et al. (2004) performed a supervised classification to produce a five-class land cover map of the boreal forests of Finland, and again, combined the land cover information with patch statistics and topographic data to predict the distribution of selected bird species. Areas of high predictedbird-species richness in the boreal agricultural-forest mosaic were found mainly concentrated along river valleys with steep topography. Analysis indicated that the explanatory power of the topography-moisture models increased when the composition and land cover information, derived from remote sensing, were included.

Rather than undertaking a broad land cover classification, Peery et al. (1999) classified TM imagery into seven classes, using a supervised classification approach which captured a range of conifer age classes, as well as aspen stands, to predict Mexican spotted owl (Strix occidentalis lucida) distributions. Raw spectral bands and image band ratios were combined with topographic data in the final classification. Habitat composition and suitability was then assessed by overlaying the mapped home ranges of the species. Results indicated that Mexican spotted owls occurred in sites with more mature, mixed conifer species, and with proportionally less pinyon pine, than random sites on the landscape.

Miller and Conroy (1990) employed slightly finer SPOT High Resolution Visible (HRV) imagery (20 m spatial resolution) and a supervised classification to predict seven land cover classes ranging from agriculture and native grasses to a variety of broadleaf successional stages. Maps of the early seral stages were then linked to potential habitat for the Kirtland's warbler (Dendroica kirtlandii), an endangered species wintering in the Bahamas. In their conclusions, Miller and Conroy (1990) highlighted that remotely sensed data provided critically important information due to its timeliness and ability to provide information on vegetation composition in areas which were logistically difficult to access.

In a number of countries, remote sensing-based land cover maps have been generated over extensive areas, and are publicly available (for example, the 2001 National Land Cover Database of the United Stated - http://www.mrlc.gov; the Land Cover Map of Great Britain - http://www.ceh.ac.uk/data; and the land cover map of the forested region of Canada - http://www.pfc.forestry.ca/EOSD). Cardillo et al. (1999) assessed the benefit of a remote sensing-derived land cover map of Great Britain based on a supervised classification of land cover with 25 classes. These land cover maps were aggregated to a $1 \times 1 \mathrm{~km}$ grid and then related to the richness and occurrence of 29 terrestrial mammals from four regions of Britain. 
Results indicated that over the entire country, the predictive power of the land cover information was poor and explained less than half of the variation in mammal species richness and occurrence. This predicative ability was considerably stronger however when the country was stratified into regions and analyzed separately $\left(R^{2}=0.21-0.55\right.$ for the stratified regions, versus $R^{2}=0.05-0.29$ for the aggregated data). The same land cover dataset was also used by Fuller et al. (2005) to examine bird habitat preferences across south-eastern England. They found the land cover products to be an effective way to link predictions of bird species richness to habitat, and that the maps captured strong regional patterns associated with distinctive habitat assemblages. The authors concluded that remote sensing was an excellent tool to assess habitats, comprehensively, over large areas.

In addition to birds, remote sensing technology has also been used to map land cover in support of other wildlife studies. Waller and Mace (1997) utilized a Landsat TM supervised classification to obtain seven land cover classes to predict grizzly bear (Ursus arctos) populations in Montana, US. Results indicated the bears utilized avalanche chutes and slab rock (classified as soil and bare ground) all year round, whereas shrub and timber harvest areas were selected relative to availability in summer and fall. Clear patterns of movement were also differentiated using a combination of the land cover maps with data from radio-collared bears. Recent work with grizzly bears in Alberta (Nielsen et al. 2006) has examined relationships between spatial landscape structure, human-caused landscape change, grizzly bear health and population performance through combined use of remote sensing technology, Global Positioning System (GPS) radio-telemetry, wildlife health evaluation, and molecular techniques.

Elk (Cervus canadensis) habitat mapping was undertaken by Huber and Casler (1990) in Colorado, US. Again, a land cover map was produced using a supervised classification with 13 classes of forest, grass, and shrub communities. Results showed that the large number of detailed forest classes resulted in significant misclassification of some of the key classes critical for elk habitat mapping. The study concluded caution should be exercised when attempting to classify highly-detailed land cover types, which may not appear spectrally distinct from other classes in satellite data.

In the above cases, satellite remote sensing imagery was classified using a supervised approach, wherein the user guides the land cover classes being created through training data. Unsupervised classification involves the statistical examination of a sample of image pixels with the goal of dividing the image into spectral classes based on the inherent spectral clusters present within the image. Unlike supervised classification, unsupervised approaches do not require the user to specify training data to initiate the process, rather classes are labeled after the classification process based on ground truth information. Debinski et al. (1999) used an unsupervised classification approach on Landsat TM imagery to produce an initial separation of 50 classes, which allowed for subsequent discrimination of gross land cover types, both individually and along a hydrological gradient. Each spectral class was subsequently identified and labelled using aerial photography and personal knowledge of the study area, resulting in a detailed and locally-specific vegetation map. Six non-forested meadow classes, representing a distinct xeric-to-hydric gradient, were 
mapped and correlated to the abundance of a number of butterfly and bird species. Results indicated that the sites of highest species richness coincided for both birds and butterflies, and could be found predominately in the mesic meadows. Hatten and Paradzick (2003) employed a similar unsupervised classification routine to map vegetation and floodplain land cover types, developing a relationship with southwestern flycatcher habitat in Arizona, US. The method provided a basis for predicting landscape configuration at both the local site location and environments $200 \mathrm{~km}$ further away.

In the tropics, Ortega-Huerta and Medley (1999) performed an unsupervised classification on Landsat TM imagery to derive a range of land cover classes for input into a jaguar (Panthera onca) habitat suitability model for sites in Mexico. Land cover classes were combined with topography and hydrological layers to map optimum jaguar habitat and provide management criteria to maintain and further enhance available habitat. Similarly, Cua on (2000) compared land cover and land cover change data from 1974 to 1986 derived from Landsat MSS data to a number of mammal abundance records in Neotropical regions of South America. Results indicated that there was a declining trend in the amount of habitat suitable for approximately $59 \%$ of the tropical species examined.

Image classification techniques can also be applied to high-spatial-resolution imagery from satellite or airborne platforms. Dechka et al. (2002), for example, applied both supervised and unsupervised techniques on two Ikonos satellite images (4 $\mathrm{m}$ spatial resolution) to map a number of wetland habitat classes and vegetation communities in southern Saskatchewan, Canada. A number of image processing approaches were used, resulting in a range of accuracies of land cover classes, including a key wetland habitat class used to map waterfowl and migratory bird patterns across central Canada.

\subsection{Biomass and Primary Production}

There is strong evidence that contemporary climate drives broad-scale species richness gradients of both plants and animals (Hawkins et al. 2003). For plants, it is widely accepted that energy and water together drive diversity and form (Currie and Paquin 1987; Leathwick et al. 1998; Francis and Currie 2003). For animals, energy either alone or in combination with water has been linked to large-scale variation in diversity, depending largely on the location in the world the study is focused (Hawkins et al. 2003). Primary production can be derived using remotely sensed data by examining the spectral reflectance centered on the near-infrared and visible red bands of the electromagnetic spectrum. Within-leaf scattering is high in the near-infrared region, thus the reflectance signal returned from the canopy is also high in this spectral region. In contrast, the red wavelengths of the electromagnetic spectrum are selectively absorbed by leaf pigments, which results in low reflectance in these bands (Coops et al. 2007). As a consequence, foliage area and increasing photosynthetic activity are correlated to the contrast in reflectance between near-infrared 
and red wavelengths. The Normalized Difference Vegetation Index (NDVI) is the most common and widely-applied of these vegetation indices. NDVI has been used as an estimator of 'greenness' (Stow et al. 2007) and a surrogate for large number of vegetation attributes, including biomass, leaf area index, phytomass, amount of green cover, productivity, photosynthetic activity, and leaf nitrogen content (Turner et al. 1992; Huete et al. 1994; Asner and Wessman 1997).

Bailey et al. (2004) computed the annual maximum value of Landsat NDVI to provide an estimate of maximum annual primary productivity and the relationship between this measure of productivity and its spatial heterogeneity and bird and butterfly species richness was then examined. Positive linear relationships between the Landsat imagery and the number of functional guilds of birds and species richness of neotropical migrant birds were found. Spatial variation in NDVI however was negatively correlated with number of functional guilds, and species richness, of resident birds. In a more species-specific study, Wallin et al. (1992) analyzed a time sequence of 1-km NDVI data from the NOAA Advanced Very High Resolution Radiometer (AVHRR) sensor to relate vegetation dynamics to potential breeding habitat of the African weaver-bird. The very large continental spatial scale of the imagery, combined with the highly mobile nature of the species, made the scale of the datasets well-matched. The results demonstrated that coarse-spatial-resolution satellite data could be effectively used to monitor potential breeding habitat through time. Relationships between avian species diversity and annual vegetative biomass were also found in Senegal using broad-scale satellite information on vegetation greenness (Jorgensen and Nohr 1996). Similarly, Skidmore et al. (2003) predicted mammal and bird species richness using broad-scale (1 km spatial resolution) satellite indicators of vegetation greenness. However, they noted that climate parameters were better predictors of species richness than the satellite data alone. Bonn et al. (2004) used a similar approach to investigate the relationship between species richness and productivity, and found that higher productivity levels do relate to higher levels of species richness.

Rodriguez et al. (2005) utilised a global vegetation index (GVI - an indicator of standing plant biomass), obtained from the AVHRR at $1 \mathrm{~km}$ spatial resolution to predict amphibian richness. Results indicated that while potential evaporation was the best explanatory variable overall, plant biomass derived from GVI was almost as good as potential evaporation at predicting amphibian richness, suggesting that plant productivity plays a role in determining diversity for this group. Van Bommel et al. (2006) used NDVI from a number of seasonal Landsat TM scenes to develop subclasses of broad physiognomic vegetation types in Botswana and related them to the occurrence of impala at landscape scales, under seasonally varying conditions. Results indicated that impala displayed selectivity for vegetation subclasses assigned on the basis of NDVI characteristics only, and not climate, allowing simple population models to be developed. Given the recent progress in the fields of satellite tracking of animals in the field (Amstrup et al. 2004) and vegetation condition assessment using the NDVI and other indices, a strong link between animal movements and functional vegetation analysis using remote sensing was proposed. Earlier, Verlinden and Masogo (1997) utilized AVHRR-derived NDVI and found 
excellent relationships between NDVI and green grass conditions in the Kalahari of Botswana. Based on these predictions of green cover, the density and distributions of a number of species, including wildebeest, hartebeest and ostrich, were made. In general, relationships between NDVI and animal distribution were difficult to test using the available presence/absence data. However, results indicated that both ostrich and wildebeest were associated with areas with higher NDVI. The authors concluded that NDVI from AVHRR data could be used to monitor suitable habitat in the wet season for some abundant species that preferentially select green patches in their environment.

In a study which attempted to employ phenological information from NDVI time series, Stow et al. (2004) used the annual median and rate of change of NDVI to estimate the quality and quantity of green forage that was available to the Porcupine caribou herd in northern Alaska and the Yukon Territory of Canada. At the broad scale, females were found to select annual calving grounds with a high proportion of easily-digestible forage (characterized by a high rate of NDVI increase), and then locally select concentrated calving areas with relatively high plant biomass. The amount of forage available at peak lactation times of the year provided the best model of calf survival. The authors concluded the timing of snowmelt and vegetation phenology influenced both the annual selection of calving areas and subsequent survival rate of the calves. Similarly, Nilsen et al. (2005) linked satellite measured greenness with measures of fauna diversity by comparing variations in the mean and seasonal greenness over a two year period with the home ranges of 12 carnivore species in the northern hemisphere, testing the hypothesis of Harestad and Bunnell (1979) that species' home ranges should decrease as a function of increasing productivity. Results indicated that the accuracy of prediction of eight of the 12 species' home range sizes was improved through the inclusion of satellite estimated greenness.

\subsection{Energy Relations}

In grasslands in particular, information on vegetation productivity and biomass can be combined with remotely sensed estimates of land surface temperature. As NDVI increases over grasslands, a linear decrease in surface temperature can be observed. This pattern is ascribed to an increase in latent heat flux away from the surface due to transpiration by grassland plants. While this relationship changes based on land cover type and season, it can be exploited to describe the moisture availability of the landscape (Hill 2004). This type of analysis has been applied in epidemiology studies such as estimating risk for the snail-borne diseases caused by Schistosoma spp. and Fasciola spp. Models using NDVI and temperature data derived from the AVHRR over regions of Ethiopia explained over $90 \%$ of the variance in observed snail sample sites (Kristensen et al. (2001).

Torgersen et al. (1999) utilized remotely sensed stream temperature data to evaluate changes in the riverine habitat and thermal spatial structure that may influ- 
ence the distribution patterns of Chinook salmon (Oncorhynchus tshawytscha). Using airborne thermal imagery, at 20-60 cm spatial resolution in north-eastern Oregon, results indicated that cool-water temperature patterns were strongly related to salmon distributions. The authors concluded that the heterogeneity of thermal properties in streams should be recognized for their biological potential to provide habitat information for species existing near the margin of their environmental tolerances.

\subsection{Chemical/Pigment Constituents}

An important application for remote sensing technology, in addition to the classification of land cover and habitat types and the prediction of biomass, is the detection of different vegetation characteristics based on underlying pigment and chemical constituents. These differences in the composition of vegetation are often difficult to detect, since the changes are often subtle and gradual, with species having many similar spectral characteristics. These surveys however can be successfully undertaken using data with very fine spectral resolution, allowing finer detail in the spectral signatures of vegetation to be examined. This type of remote sensing imagery is available predominately from airborne sensors, such as the Airborne Visible/Infrared Imaging Spectrometer (AVIRIS) and the Compact Airborne Spectrographic Imager (CASI). Most recently, however, the Hyperion sensor onboard the Earth Observer (EO1) satellite platform, launched in 2000, provides similar imagery over larger areas in a more cost-effective manner. Finally, spectra can also be obtained from hand-held instruments, using near-infrared reflectance spectroscopy, allowing for in situ estimation of detailed vegetation properties.

Initial research in this area was undertaken by Norris et al. (1976) who utilized near-infrared-reflectance spectra of 87 samples of ground dry forages such as alfalfa and tall fescue. Multiple-linear-regression techniques were used to determine the optimum wavelengths for predicting each of the chemical concentrations, with the authors concluding that infrared reflectance has the potential to assist in the rapid evaluation of forage quality.

McIlwee et al. (2001) investigated the potential of hand-held reflectance spectroscopy as to assess the chemical constituents of Eucalyptus leaves in Australia, and thus directly assess the quality of intake of foliage by gliders and possums. The authors concluded that concentrations of foliar nitrogen, tannins, and phenolics could be estimated using regression approaches correlating near-infrared reflectance spectra of foliage samples. Spectral-based models of food intake were found to be highly accurate for both species, and these models were then used to assess the food intake for gliders and examine the relationship between leaf palatability and food preferences of the mammals. Differences in leaf palatability for a number of tree species were consistent with the known food preferences of greater gliders, and it was concluded that field-based spectroscopy provides a powerful tool for predicting the foraging behavior of herbivores in situations where forage choices are determined by the compositional attributes of food. In a follow-on study, Dury et al. (2001) assessed the feasibility of extending the results spatially across larger areas using airborne 
remotely-sensed canopy biochemistry. Using laboratory spectra, they first reported on developing calibration equations for key concentrations based on the reflectance spectra, then scaled-up the relationships using airborne hyperspectral imagery (HYMAP). Strong correlations were found to exist between canopy-level pigment contractions and mean spectra. The study also identified several other spectral bands that corresponded to other key chemical concentrations, with the authors concluding that airborne HYMAP data could be used to estimate selected foliage chemical concentrations at the canopy level with acceptable accuracy (Huang et al. 2002).

\subsection{Non-Photosynthetic Vegetation}

In addition to live vegetation components, information on dry plant materials such as dry leaves, dry reproductive structures, bark, and woody debris can also provide important insights to wildlife populations and abundance, due to their key roles as both food source and shelter. Elvidge (1990) acquired very fine, hand-held spectra of green leaf (or green stem), senesced leaf, decayed leaf, brown wood, grey wood and bark for eight tree species including sagebrush, pinyon pine, white peppermint and sycamore. Results showed that the spectral features of dry plant materials bear little resemblance to those of green leaves. Green leaf spectra are dominated by the spectral features of chlorophyll and water, but when leaf senescence occurs these two compounds are lost and a host of previously-masked spectral features emerge. Elvidge (1990) concluded that all previous vegetation indices had been based on the spectral features of green vegetation. The development of vegetation indices for dry plant materials will be of major utility in assessing the biomass and biochemistry of dormant plant communities, vegetation stress, and measuring fuel loadings in areas subject to fire, and may also have a key role to play in biodiversity assessment.

Following on these ideas, Kawamura et al. (2005) employed AVHRR and Moderate Resolution Imaging Spectroradiometer (MODIS) sensors to detect seasonal vegetation changes (phenology) with regard to forage quantity and quality, focusing on, amongst others, attributed dead standing biomass. The dynamic range of the MODIS NDVI was analyzed and its sensitivity in discriminating between vegetation differences was evaluated across sparsely- and densely-vegetated areas. Results suggested that the MODIS NDVI can reliably detect the phenology and attributed dead biomass forage quantity and quality of grassland steppe areas.

In research on understory fuel loads associated with fire potential, Roberts et al. (1992) developed techniques to map non-photosynthetic vegetation (NPV), shade, and soil from a hyperspectral AVIRIS airborne image, and then interpreted these maps in an ecological context. Results confirmed the maps of NPV were distinguished from soil through spectral variations attributed to lignin and cellulose. These types of spatial predictions, in addition to being useful for fire fuel estimation, have direct relevance on wildlife habitat, wherein these components provide food, shelter, and grazing (Wessman et al. 1997). Similarly Jia et al. (2006) used airborne AVIRIS imagery to map major forest components in montane coniferous 
forests in Colorado, US. Again, mapping the fractional covers of NPV and bare soil proved critical, with high fractions of NPV and bare soil found in areas with recent disturbance such as fire or insect infestation.

\subsection{Vertical Vegetation Structure}

Thus far, all the techniques discussed in this chapter have employed passive satellite or airborne data. These systems, such as Landsat, collect data by sensors operating in the visible and infrared regions of the spectrum, designed primarily to detect reflected light and temperature (such as weather or meteorological satellites). Alternatively, active remote sensing systems are those that emit energy, in one form or another, and then measure the rate or amount of return back to the instrument. Active sensors can therefore operate under expanded meteorological conditions, since solar illumination is not required. The choice of active versus passive systems for vegetation structural mapping will depend primarily on the information need. Since active sensors can operate regardless of weather, they may be most effectively used in areas where there is perpetual cloud cover (e.g. tropical rainforests) (Lefsky and Cohen 2003). Synthetic aperture radar (SAR) is one form of radar remote sensing that utilizes microwave wavelengths many times longer than that of visible light. Terrestrial lidar sensors typically capture data at a single spectral band, often between 900 and 1,064 nm using cohesive laser beams operating primarily on airborne platforms.

Information on vertical vegetation structure is difficult to quantify from passive remote sensing technology, and yet is a key mechanism underlying many wildlifehabitat models. Manual survey of vegetation structure becomes prohibitive in terms of time and cost if sampling needs to be of sufficient density to characterize finegrained heterogeneity at a landscape extent (Bradbury et al. 2005). Zimble et al. (2003) characterized a suite of vertical and horizontal forest attributes at fine scales for inclusion in decision-support systems in central Idaho. Analysis of field-derived tree height variance demonstrated that this metric could accurately distinguish between single-storey and multi-storey vertical structural classes.

Mason et al. (2003) used a combination of lidar and high-spatial-resolution optical data to extract information on landscape and vegetation structure at a spatial scale fine enough to match the fine-grained predictor variables used in most wildlife-habitat models. Results for the predicted abundance of two bird species, the sky lark and the great/blue tits, indicated that the derivation of vegetation structure data from airborne lidar has several clear advantages over field surveys in the construction of habitat models. First, the vertical resolution and sampling density of the data is equivalent or better than that which can be achieved by field measurement; second, the vertical and horizontal resolution available from LIDAR is scalable to landscape scales; and finally, the predicted attributes from these data allow heterogeneity in vegetation structure to be expressed at a variety of spatial scales, ranging from the foraging patch or territory to landscape (Bradbury et al. 2005). 
Nelson et al. (2005) utilized an extensive lidar dataset over the state of Delaware to identify forested sites that potentially could support Delmarva fox squirrel (DFS; Sciurus niger cinereus) populations, an endangered species endemic to mature forests with open understories. The study indicated that, based on site characteristics of known habitat, a systematic airborne lidar data can be used to screen extensive areas of forest to locate potential DFS habitat, and that over $70 \%$ of locations met the canopy structural criteria thus supporting DFS populations, according to a habitat suitability model. The authors recommended also that a systematic survey across the county and state could be developed and undertaken at regular intervals to monitor changes to the areal extent of potential habitat over time.

In contrast to lidar data, radar remote sensing employs microwave energy emitted from airborne or spaceborne antennas, rather than laser bursts. These microwave pulses are emitted and received at wavelengths from $1 \mathrm{~cm}$ to $1 \mathrm{~m}$ and are configured on either a single vertical or horizontal plane (known as polarization; Coops 2002). Operationally designated wavelengths for radar are $3 \mathrm{~cm}$ (X-band), $5.5 \mathrm{~cm}$ (C-band), $24 \mathrm{~cm}$ (L-band) and $68 \mathrm{~cm}$ (P-band). Surfaces inclined towards the radar will have a stronger reflection (termed backscatter) than those which slope away from the radar. As a result, smooth flat surfaces will reflect little or no microwave energy and thus will appear dark in radar images. Vegetation, which is usually moderately rough at the scale of most radar wavelengths, appears gray.

A key attribute affecting the response of vegetation on radar backscatter is vegetation structure, in particular the vertical distribution of biomass through the canopy. As a result, the natural and anthropogenic processes that affect vegetation structure, such as regeneration and succession, can be readily-apparent in radar imagery. Kasischke et al. (1997) undertook a detailed review of the application of radar in ecological studies and highlighted a wide range of radar applications, including land cover classification (Henebry and Kux 1995; Hoekman and Quinones 2000), measurement of above ground woody biomass (Bergen and Dobson 1999), and delineation of wetland inundation (Falco et al. 1996). Imhoff (1995) compared forest canopy biometric data from a variety of tropical and sub-tropical forests with varying structural differences to simulated scenes of radar backscatter, showing that the structure of forest stands can have a considerable effect on backscatter amount, even when the amount above ground biomass remains equivalent. Beaudoin et al. (1994) utilized multi-polarized P-band data to document significant correlations with forest biomass, and found backscatter amount to be sensitive to a variety of ground surface attributes such as plant undergrowth, relief, and soil conditions. Yanasse et al. (1997) showed the ability of L-band, HV-polarized data to detect biomass changes occurring during tropical forest succession, and found backscatter to provide an accurate measure of biomass when soil conditions were dry. Imhoff et al. (1997) integrated aerial photography and field data with P-, L-, and C-band SAR data obtained from NASA's airborne AIRSAR system to study landscape spatial heterogeneity and bird community ecology at Kakadu National Park in Australia. Results indicated that SAR data were able to discern structural vegetation differences, and that multispectral sensors successfully identified floristic differences relevant to bird habitat quality. The authors concluded that the developed approaches advanced the use of 
SAR data for three-dimensional mapping of animal habitats from remotely sensed data (Imhoff et al. 1997).

Dobson et al. (1995) used multi-polarized SAR data and ancillary terrain information to estimate a range of forest structural attributes in boreal forests of Northern Michigan, including basal area, height, and dry crown biomass. Results indicated that biophysical attributes could be estimated with relatively small errors from SAR data, and that the combination of shorter wavelengths ( $\mathrm{X}$ and C) yielded substantial improvements in estimates of crown biomass. Despite this success, a number of other studies have found SAR to be unresponsive to biomass when a certain threshold has been reached. For example Rauste et al. (1994) found that L-band SAR reached saturation at $70 \mathrm{mg} / \mathrm{ha}$. The recent launch of advanced satellite-based SAR platforms, including the Canadian 3-m-resolution, fully polarimetric RADARSAT-2 instrument, potentially promises future advances on this front.

Demonstrating the exciting potential of integrated passive and active remote sensing data sets, Hyde et al. (2006) investigated the estimation of structural information from lidar, SAR, and optical sensors including Landsat to combine the highly-accurate vertical information available from active remote sensing with the broad-scale capabilities of optical imagery. The results indicated that while lidar was the best single dataset for estimating stand height and biomass, the use of Landsat metrics in addition, improved the prediction of large tree structures. Results also showed that high-spatial-resolution Quickbird imagery improved estimates only marginally when compared to the lidar datasets, however the combination of all sensors combined was better than lidar alone, however only slightly better than the dual combination of lidar and Landsat.

Despite the overriding message here that active remote sensing instruments are better-suited for extracting vegetation structural information, a number of authors have reported considerable success using passive high-spatial-resolution optical imagery from either satellite or airborne systems (Wulder et al. 2004). These include estimation of individual crown closure (Cohen et al. 1995, 2001), prediction of stem density and stand height (Franklin and McDermid 1993), and classification of relative stand age or stage of development (Cohen et al. 1995, 2001; Franklin et al. 2001; Nelson et al. 2005). Employing high-spatial-resolution imagery to extract structural attributes also lends itself to the use of textural attributes, which can provide information on stand crown gaps (Blackburn and Milton 1997) and foliage estimation (Wulder et al. 1998). Additionally, the derivation of image variance and semivariance to provide measures of stand structure (St-Onge and Cavayas 1997; Wulder et al. 1998; Levesque and King 2003), and the fitting of spatial statistical models such as semivariograms to represent forest structure (Levesque and King 2003), has also been successful. In this latter approach, the semivariogram range, sill, and nugget are fitted to image objects and subsequently interpreted. For example, Coops and Catling (1996) used a modified local variance method that assessed the changes in the standard deviation of a moving $3 \times 3$ window on successively spatially degraded images. A relationship was then developed that related the maximum level of variance observed with the vertical distribution of biomass within 
a forested canopy. These assessments were then applied to estimate mammalian distributions and abundances over large areas (Coops and Catling 2002).

\subsection{Energy Relations}

In grasslands in particular, information on vegetation productivity and biomass can be combined with remotely sensed estimates of land surface temperature. As NDVI increases over grasslands, a linear decrease in surface temperature can be observed. This pattern is ascribed to an increase in latent heat flux away from the surface due to transpiration by grassland plants. While this relationship changes - based on land cover type and season - it can be exploited to describe the moisture availability of the landscape (Hill 2004). This type of analysis has been applied already in epidemiology studies driving risk models for the snail-borne diseases caused by Schistosoma spp. and Fasciola spp. Models using NDVI and temperature data derived from the AVHRR over regions of Ethiopia explained over $90 \%$ of the variance in observed snail sample sites (Kristensen et al. 2001).

Torgersen et al. (1999) utilized remotely sensed steam temperature data to evaluate changes in the riverine habitat and thermal spatial structure that may influence the distribution patterns of Chinook salmon (Oncorhynchus tshawytscha). Using airborne thermal imagery, at $20-60 \mathrm{~cm}$ spatial resolution in north-eastern Oregon, results indicated that cool-water temperature patterns were strongly related to salmon distributions. The authors concluded that the heterogeneity of thermal properties in streams should be recognized for their biological potential to provide habitat information for species existing near the margin of their environmental tolerances.

\subsection{An Application Framework}

An application framework is a strategy for optimizing the appropriate remote sensing data and methods in an ecological context (Phinn et al. 2003). The process consists of a number of steps, including: (1) identifying the information requirements for the project (e.g. McDermid et al. 2005); (2) organizing the information needs into an ecological hierarchy (e.g. Franklin and Woodcock 1997); (3) conducting an exploratory analysis using existing digital data (e.g. Franklin 2001); (4) identifying the ideal remote sensing data, considering spatial, spectral, radiometric, and temporal resolutions (e.g. Lefsky and Cohen 2003; Coops et al. 2006); (5) selecting and applying a suitable set of processing strategies to extract the required information (e.g. Wulder 1998; Campbell 2007); and (6) conducting a cost-benefit analysis (e.g. de Bruin and Hunter 2003). In developing this application framework for ecological studies, Phinn et al. (2003) stressed the importance of the (typically) interdisciplinary analysis team understanding that the specifications for the ideal remote sensing data can vary, depending on vegetation conditions, study area size, 
and available image processing techniques. The choice of data should dictate - at least initially - the subsequent image processing techniques to be pursued: in general, classification for H-resolution data and per-pixel modeling for L-resolution imagery. Assessing the benefits of the resulting investment should take into account, among other things, the accuracy of the information products generated, the value of the resulting habitat maps, and the utility of the vegetation database for other resource management applications.

Acknowledgements The authors are grateful for support from the Natural Sciences and Engineering Research Council of Canada, the Canadian Forest Service, the Alberta Innovation and Science Fund, and the many partners and colleagues in the Foothills Model Forest Grizzly Bear Research Program.

\section{References}

Amstrup SC, McDonald TL, Durner GM (2004) Using satellite radiotelemetry data to delineate and manage wildlife populations. Wildl Soc Bull 32:661-679.

Anderson JR, Hardy EE, Roach JT, Witmer E (1976) A land use and land cover classification system for use with remote sensor data. U.S. Geological Survey Professional Paper 964. Washington, DC.

Asner GP, Wessman CA (1997) Scaling PAR absorption from the leaf to landscape level in spatially heterogeneous ecosystems. Ecol Model 103:81-97.

Atkinson PM, Lewis P (2000) Geostatistical classification for remote sensing: an introduction. Comput Geosci 26:361-371.

Atkinson PM, Cutler EJ, Lewis H (1997) Mapping sub-pixel proportional land cover with AVHRR imagery. Int J Remote Sens 18:917-935.

Austin GE, Thomas CJ, Houston DC, Thompson DBA (1996) Predicting the spatial distribution of buzzard Buteo buteo nesting areas using a Geographical Information System and remote sensing. Journal of Applied Ecology 33(6): 1541-1550.

Bailey SA, Horner-Devine MA, Luck G, Moore LA, Carney KM, Anderson S, Betrus C, Fleishman E (2004) Primary productivity and species richness: relationships among functional guilds, residency groups and vagility classes at multiple spatial scales. Ecography 27:207-217.

Beaudoin A, Letoan T, Goze S, Nezry E, Lopes A, Mougin E, Hsu CC, Han HC, Kong JA, Shin RT (1994) Retrievel of forest biomass from SAR data. Int J Remote Sens 15:2777-2796.

Benz UC, Hofmann P, Willhauck G, Lingenfelder I, Heynen M (2004) Multi-resolution, objectoriented fuzzy analysis of remote sensing data for GIS-ready information. Int J Photogram Remote Sens 58:239-258.

Bergen KM, Dobson MC (1999) Integration of remotely sensed radar imagery in modeling and mapping of forest biomass and net primary production. Ecol Model 122:257-274.

Blackburn GA, Milton EJ (1997) An ecological survey of deciduous woodlands using airborne remote sensing and geographical information systems (GIS). Int J Remote Sens 18:1919-1935.

Bonn A, Storch D, Gaston KJ (2004) Structure of the species-energy relationship. Proc R Soc Lond B Biol Sci 271:1685-1691.

Bradbury RB, Hill RA, Mason DC, Hinsley SA, Wilson JD, Balzter H, Anderson GCA, Whittingham MJ, Davenport IJ, Bellamy PE (2005) Modelling relationships between birds and vegetation structure using airborne LiDAR data: a review with case studies from agricultural and woodland environments. Ibis 147:443-452.

Braun CE (2005) Techniques for wildlife investigations and management. The Wildlife Society (TWS), Bethesda, MD. 
Burnett C, Blaschke T (2003) A multi-scale segmentation/object relationship modelling methodology for landscape analysis. Ecol Model 168:233-249.

Campbell JB (2007) Introduction to remote sensing. The Guilford Press, New York.

Cannon RW, Knopf FL, Pettinger LR (1982) Use of Landsat data to evaluate lesser prairie chicken habitat in western Oklahoma. J Wildl Manage 46:915-922.

Cardillo M, Macdonald DW, Rushton SP (1999) Predicting mammal species richness and distributions: testing the effectiveness of satellite-derived land cover data. Landsc Ecol $14: 423-435$.

Carr JR, de Miranda FP (1998) The semivariogram in comparison to the co-occurrence matrix for classification of image texture. IEEE Transact Geosci Remote Sens 36:1945-1952.

Cohen WB, Goward SN (2004) Landsat's role in ecological applications of remote sensing. Bioscience 54:535-545.

Cohen WB, Spies TA (1992) Estimating structural attributes of douglas-fir western hemlock forest stands from Landsat and SPOT imagery. Remote Sens Environ 41:1-17.

Cohen WB, Spies TA, Fiorella M (1995) Estimating the age and structure of forests in a multiownership landscape of western Oregon, USA. Int J Remote Sens 16:721-746.

Cohen WB, Maiersperger TK, Spies TA, Oetter DR (2001) Modelling forest cover attributes as continuous variables in a regional context with Thematic Mapper data. Int J Remote Sens 22:2279-2310.

Cohen WB, Maiersperger TK, Gower ST, Turner DP (2003) An improved strategy for regression of biophysical variables and Landsat ETM+ data. Remote Sens Environ 84:561-571.

Coops NC (2002) Eucalypt forest structure and synthetic aperture radar backscatter: a theoretical analysis. Trees Struct Funct 16:28-46.

Coops NC, Catling PC (1996) Utilising airborne multispectral videography to predict habitat complexity in eucalypt forests for wildlife management. Wildl Res 24:691-702.

Coops NC, Catling PC (2002) Prediction of the spatial distribution and relative abundance of ground-dwelling mammals using remote sensing imagery and simulation models. Landsc Ecol 17:173-188.

Coops NC, Wulder MA, White J (2002) Identifying and describing forest disturbance and spatial pattern: data selection issues and methodological implications. Forest disturbance and spatial pattern: remote sensing and GIS approaches. Taylor and Francis, Boca Raton, FL.

Coops NC, Wulder M, White JC (2006) Identifying and describing forest disturbance and spatial pattern: data selection issues and methodological implications. In Wulder M, Franklin SE Forest Disturbance and Spatial Pattern: Remote Sensing and GIS Approaches. Taylor and Francis. CRC Press. pp. 33-60.

Coops NC, Black TA, Jassal, RPS, Trofymow JAT, Morgenstern K (2007) Comparison of MODIS, eddy covariance determined and physiologically modelled gross primary production (GPP) in a Douglas-fir forest stand. Remote Sens Environ 107:385-401.

Csillag F, Kabos S (2002) Wavelets, boundaries, and the spatial analysis of landscape pattern. Ecoscience 9:177-190.

Cuaŕon AD (2000) Effects of land-cover changes on mammals in a neotropical region: a modelling approach. Conserv Ecol 14(4):1676-1692.

Currie DJ, Paquin V (1987) Large-scale biogeographical patterns of species richness of trees. Nature 329:326-327.

Daszak P, Cunningham AA, Hyatt AD (2001) Anthropogenic environmental change and the emergence of infectious diseases in wildlife. Acta Trop 78:103-116.

de Bruin S, Hunter GJ (2003) Making the trade-off between decision quality and information cost. Photogram Eng Remote Sens 69:91-98.

Debinski DM, Kindscher K, Jakubauskas ME (1999) A remote sensing and GIS-based model of habitats and biodiversity in the Greater Yellowstone Ecosystem. Int J Remote Sens 20:3281-3291.

Dechka JA, Franklin SE, Watmough MD, Bennett RP, Ingstrup DW (2002) Classification of wetland habitat and vegetation communities using multi-temporal Ikonos imagery in southern Saskatchewan. Can J Remote Sens 28:679-685. 
Dobson MC, Ulaby FT, Pierce LE (1995) Land-cover classification and estimation of terrain attributes using synthetic aperture radar data. Remote Sens Environ 51:199-214.

Dury SJ, Turner BJ, Foley WJ (2001) Can hyperspectral data be used to map koala and possum habitat? Pages 1648-1650 IGARSS 2001.

Elvidge CD (1990) Visible and near-infrared reflectance characteristics of dry plant materials. Int J Remote Sens 11:1775-1795.

Falco T, Francis F, Lovejoy S, Schertzer D, Kerman B, Drinkwater M (1996) Universal multifractal scaling of synthetic aperture radar images of sea-ice. IEEE Trans Geosci Remote Sens 34:906-914.

Farnsworth ML, Wolfe LL, Hobbs NT, Burnham KP, Williams ES, Theobald DM, Conner MM, Miller WM (2005) Human land use influences chronic wasting disease prevalence in mule deer. Ecol Appl 15:119-126.

Fassnacht KS, Cohen WB, Spies TA (2006) Key issues in making and using satellite-based maps in ecology: a primer. For Ecol Manage 222:167-181.

Francis AP, Currie DJ (2003) A globally consistent richness-climate relationship for angiosperms. Am Naturalist 161:523-536.

Franklin SE (2001) Remote sensing for sustainable forest management. Lewis Publishers, New York.

Franklin SE, McDermid GJ (1993) Empirical relations between digital SPOT HRV and CASI spectral response and lodgepole pine (Pinus contorta) forest stand parameters. Int J Remote Sens 14:2331-2348.

Franklin J, Woodcock CE (1997) Multiscale vegetation data for the mountains of southern California. Pages 141-168 in D. A. Quattrochi and M. F. Goodchild, editors. Scale in Remote Sensing and GIS. Lewis Publishers, New York.

Franklin SE, Wulder MA (2002) Remote sensing methods in medium spatial resolution satellite data land cover classification of large areas. Prog Phys Geog 26:173-205.

Franklin SE, Wulder MA, Gerylo GR (2001) Texture analysis of IKONOS panchromatic data for Douglas-fir forest age class separability in British Columbia. Int J Remote Sens 22: 2627-2632.

Fuller RM, Cox R, Clarke RT, Rothery P, Hill RA, Smith GM, Thomson AG, Brown NJ, Howard DC, Stott AP (2005) The UK land cover map 2000: planning, construction and calibration of a remotely sensed, user-oriented map of broad habitats. Int J Appl Earth Obs Geoinform 7:202-216.

Gillespie TW (2001) Remote sensing of animals. Prog Phys Geogr 25:355-362.

Gong P, Howarth PJ (1992) Frequency-based contextual classification and gray-level vector reduction for land-use identification. Photogram Eng Remote Sens 58:423-437.

Gottschalk T, Huettmann F (2006) Thirty years of analyzing and modeling avian habitat relationships using satellite imagery data: a review. J Ornith 147:175-175.

Graetz RD (1990) Remote sensing of terrestrial ecosystem structure. in R. J. Hobbs and H. A. Mooney, editors. Remote Sensing of Biosphere Functioning. Springer-Verlag, New York.

Greegor DH (1986) Ecology from space. Bioscience 36:429-432.

Groom GB, Fuller RM, Jones AR (1996) Contextual correction: techniques for improving land cover mapping from remotely sensed images. Int J Remote Sens 17:69-89.

Guisan A, Zimmermann NE (2000) Predictive habitat distribution models in ecology. Ecol Model 135:147-186.

Hall RJ (2003) The role of aerial photographs in forestry remote sensing image analysis. in MA Wulder and SE Franklin, editors. Remote Sensing of Forest Environments: Concepts and Case Studies. Kluwer Academic Publishers, Norwell, MA, pp 47-77.

Hall FG, Peddle DR, Ledrew EF (1996) Remote sensing of biophysical variables in boreal forest stands of Picea mariana. Int J Remote Sens 17:3077-3081.

Harestad AS, Bunnell FL (1979) Home range and body-weight - re-evaluation. Ecology 60:389-402.

Hatten JR, Paradzick CE (2003) A multiscaled model of southwestern willow flycatcher breeding habitat. J Wildl Manage 67:774-788.

Hawkins BA, Field R, Cornell HV, Currie DJ, Guegan JF, Kaufman DM, Kerr JT, Mittelbach GG, Oberdorff T, O'Brien EM, Porter EE, Turner JRG (2003) Energy, water, and broad-scale geographic patterns of species richness. Ecology 84:3105-3117. 
Hay GJ, Dube P, Bouchard A, Marceau DJ (2002) A scale-space primer for exploring and quantifying complex landscapes. Ecol Model 153:27-49.

Heinz DC, Chang CI (2001) Fully constrained least squares linear spectral mixture analysis method for material quantification in hyperspectral imagery. IEEE Trans Geosci Remote Sens 39:529-545.

Henebry GM, Kux HJH (1995) Lacunarity as a texture measure for SAR imagery. Int J Remote Sens 16:565-571.

Herr AM, Queen LP (1993) Crane habitat evaluation using GIS and remote sensing. Photogrammetric Engineering and Remote Sensing 59:1531-1538.

Hill M (2004) Grazing agriculture: managed pasture, grassland, and rangeland. Pages 449-529 in S. Ustin, editor. Remote Sensing for Natural Resource Management and Environmental Monitoring. John Wiley \& Sons, Hoboken, NJ.

Hoekman DH, Quinones MJ (2000) Land cover type and biomass classification using AirSAR data for evaluation of monitoring scenarios in the Colombian Amazon. IEEE Trans Geosci Remote Sens 38:685-696.

Huang ZXJ, Turner B, Foley W, Dury S (2002) Use of HYMAP image data to estimate sideroxylonal-A concentration of eucalypt foliage. Pages 1652-1654 IGARSS 2002.

Huber TP, Casler KE (1990) Initial analysis of Landsat TM data for elk habitat mapping. Int J Remote Sens 11:907-912.

Huete A, Justice C, Liu H (1994) Development of vegetation and soil indexes from MODIS-EOS. Remote Sens Environ 49:224-234.

Hyde P, Dubayah R, Walker W, Blair JB, Hofton M, Hunsaker C (2006) Mapping forest structure for wildlife habitat analysis using multi-sensor (LiDAR, SAR/InSAR, ETM plus, Quickbird) synergy. Remote Sens Environ 102:63-73.

Imhoff ML (1995) A theoretical analysis of the effect of forest structure on synthetic aperture radar backscatter and the remote sensing of biomass. IEEE Trans Geosci Remote Sens 33:341-352

Imhoff ML, Sisk TD, Milne A, Morgan G, Orr T (1997) Remotely sensed indicators of habitat heterogeneity: use of synthetic aperture radar in mapping vegetation structure and bird habitat. Remote Sens Environ 60:217-227.

Jia GJ, Burke IC, Goetz AFH, Kaufmann MR, Kindel BC (2006) Assessing spatial patterns of forest fuel using AVIRIS data. Remote Sens Environ 102:318-327.

Jorgensen AF, Nohr H (1996) The use of satellite images for mapping of landscape and biological diversity in the Sahel. Int J Remote Sens 17:91-109.

Jupp DL, Strahler AH, Woodcock CE (1988) Autocorrelation and regularization in digital images: I. Basic theory. IEEE Trans Geosci Remote Sens 26:463-473.

Jupp DL, Strahler AH, Woodcock CE (1989) Autocorrelation and regularization in digital images: II. Simple image models. IEEE Trans Geosci Remote Sens 27:247-258.

Kasischke ES, Melack JM, Dobson MC (1997) The use of imaging radars for ecological applications - a review. Remote Sens Environ 59:141-156.

Kawamura K, Akiyama T, Yokota H, Tsutsumi M, Yasuda T, Watanabe O, Wang G, Wang S (2005) Monitoring of forage conditions with MODIS imagery in the Xilingol steppe, Inner Mongolia. Int J Remote Sens 26:1423-1436.

Kay JJ (1991) A nonequilibrium thermodynamic framework for discussing ecosystem integrity. Environ Manage 15:483-495.

Kristensen TK, Malone JB, McCarroll JC (2001) Use of satellite remote sensing and geographic information systems to model the distribution and abundance of snail intermediate hosts in Africa: a preliminary model for Biomphalaria pfeifferi in Ethiopia. Acta Trop 79:73-78.

Leathwick JR, Burns BR, Clarkson BD (1998) Environmental correlates of tree alpha-diversity in New Zealand primary forests. Ecography 21:235-246.

Lefsky MA, Cohen WB (2003) Selection of remotely sensed data. Pages 13-46 in M. A. Wulder and S. E. Franklin, editors. Remote Sensing of Forest Environments: Concepts and Case Studies. Kluwer Academic Publishers, Norwell, MA.

Leimgruber P, Christen CA, Laborderie A (2005) The impact of Landsat satellite monitoring on conservation biology. Environ Monit Assess 106:81-101. 
Levesque J, King DJ (2003) Spatial analysis of radiometric fractions from high-resolution multispectral imagery for modelling individual tree crown and forest canopy structure and health. Remote Sens Environ 84:589-602.

Lewis M (2003) Inventing global ecology: tracking the Biodiversity Ideal in India 1945-1997. Orient Longman, New Delhi.

Luckman A, Baker J, Kuplich TM, Yanasse CDF, Frery AC (1997) A study of the relationship between radar backscatter and regenerating tropical forest biomass for spaceborne SAR instruments. Remote Sens Environ 60:1-13.

Lunetta RS, Elvidge C (1998) Remote sensing change detection: enviromental monitoring methods and applications. Ann Arbor Press, Chelsea, MI.

Luoto M, Virkkala R, Heikkinen RK, Rainio K (2004) Predicting bird species richness using remote sensing in boreal agricultural-forest mosaics. Ecol Appl 14:1946-1962.

Majumdar SK, Huffman JE, Brenner F, Panah AI (2005) Wildlife diseases: landscape epidemiology, spatial distribution, and utilization of remote sensing technology. Pennsylvania Academy of Sciences, Easton, PA.

Mason DC, Anderson GCA, Bradbury RB, Cobby DM, Davenport LJ, Vandepoll M, Wilson DJ (2003) Measurement of habitat predictor variables for organism-habitat models using remote sensing and image segmentation. Int J Remote Sens 24:2515-2532.

McDermid GJ, Franklin SE, LeDrew EF (2005) Remote sensing for large-area habitat mapping. Prog Phys Geogr 29:449-474.

McIlwee AM, Lawler IR, Cork SJ, Foley WJ (2001) Coping with chemical complexity in mammal-plant interactions: near-infrared spectroscopy as a predictor of Eucalyptus foliar nutrients and of the feeding rates of folivorous marsupials. Oecologia 128:539-548.

Michaelsen J, Schimel DS, Friedl MA, Davis FW, Dubayah RC (1994) Regression tree analysis of satellite and terrain data to guide vegetation sampling and surveys. J Veg Sci 5:673-686.

Miller KV, Conroy MJ (1990) SPOT satellite imagery for mapping Kirtland's Warbler wintering habitat in the Bahamas. Wildl Soc Bull 18:252-257.

Nelson R, Keller C, Ratnaswamy M (2005) Locating and estimating the extent of Delmarva fox squirrel habitat using an airborne LiDAR profiler. Remote Sens Environ 96:292-301.

Nielsen SE, Stenhouse GB, Boyce MS (2006) A habitat-based framework for grizzly bear conservation in Alberta. Biol Conserv 130:217-229.

Nilsen EB, Herfindal I, Linnell JDC (2005) Can intra-specific variation in carnivore home-range size be explained using remote-sensing estimates of environmental productivity? Ecoscience 12:68-75.

Norris KH, Barnes RF, Moore JE, Shenk JS (1976) Predicting forage quality by infrared reflectance spectroscopy. J Anim Sci 43:889-897.

Oindo BO, Skidmore AK, De Salvo P (2003) Mapping habitat and biological diversity in the Maasai Mara ecosystem. Int J Remote Sens 24:1053-1069.

Palmeirim JM (1988) Automatic mapping of avian species habitat using satellite imagery. Oikos 52:59-68.

Parkinson CL, Greenstone R (2000) EOS Data Products Handbook. NASA/Godard Space Flight Center, Greenbelt, MD.

Peery MZ, Gutierrez RJ, Seamans ME (1999) Habitat composition and configuration around Mexican spotted owl nest and roost sites in the Tularosa Mountains, New Mexico. J Wildl Manage 63:36-43.

Phinn SR, Stow DA, Franklin J, Mertes LAK, Michaelsen J (2003) Remotely sensed data for ecosystem analyses: combining hierarchy theory and scene models. Environ Manage 31:429-441.

Plummer SE (2000) Perspectives on combining ecological process models and remotely sensed data. Ecol Model 129:169-186.

Ramanujan K (2004) New tools for conservation. Earth Observatory. http://earthobservatory.nasa. gov/Study/Conservation/printall.php accessed January 6, 2008.

Rauste Y, Hame T, Pulliainen J, Heiska K, Hallikainen M (1994) RADAR-based forest biomass estimation. Intl J Rem Sens 15:2797-2808. 
Richards JA, Jia X (2006) Remote sensing digital image analysis: an introduction. Fourth Edition. Springer-Verlag, Berlin.

Roberts DA, Smith MO, Sabol DE, Adams JB, Ustin S (1992) Mapping the spectral variability in photosynthetic and non-photosynthetic vegetation, soils, and shade using AVIRIS. Summaries of the Third Annual JPL Airborne Geoscience Workshop, Pasadena, CA, 92-14, 38-40.

Robinson IS (1985) Satellite oceanography, Chinchester, England.

Rodriguez MA, Belmontes JA, Hawkins BA (2005) Energy, water and large-scale patterns of reptile and amphibian species richness in Europe. Acta Oecologica Int J Ecol 28:65-70.

Rotunno OC, Treitz PM, Soulis ED, Howarth PJ, Kouwen N (1996) Texture processing of synthetic aperture radar data using second-order spatial statistics. Comput Geosci 22:27-34.

Sharma KMS, Sarkar A (1998) Modified contextual classification technique for remote sensing data. Photogram Eng Remote Sens 64:273-280.

Skidmore AK, Oindo BO, Said MY (2003). Biodiversity assessment by remote sensing. Proceedings of the 30th International Symposium on Remote Sensing of the Environment: Information for Risk Management and Sustainable Development.

St-Onge BA, Cavayas F (1997) Automated forest structure mapping from high resolution imagery based on directional semivariogram estimates. Remote Sens Environ 61:82-95.

Stow DA, Hope A, McGuire D, Verbyla D, Gamon J, Huemmrich J, Houston S, Racine C, Sturm M, Tape K, Hinzman L, Yoshikawa K, Tweedie C, Noyle B, Silapaswan C, Douglas D, Griffith B, Jia G, Epstein H, Walker S, Daeschner S, Petersen A, Zhou LM, Myneni R (2004) Remote sensing of vegetation and land-cover change in Arctic Tundra Ecosystems. Remote Sens Environ 89:281-308.

Stow D, Petersen A, Hope A, Engstrom R, Coulter L (2007) Greenness trends of Arctic tundra vegetation in the 1990s: comparison of two NDVI data sets from NOAA AVHRR systems. Int J Remote Sens 28:4807-4822.

Strahler AH, Woodcock CE, Smith JA (1986) On the nature of models in remote sensing. Remote Sens Environ 20:121-139.

Thogmartin WE, Gallant AL, Knutson MG, Fox TJ, Suarez J (2004) Commentary: a cautionary tale regarding use of the National Land Cover Dataset 1992. Wildl Soc Bull 32:970-978.

Torgersen CE, Price DM, Li HW, McIntosh BA (1999) Multiscale thermal refugia and stream habitat associations of chinook salmon in northeastern Oregon. Ecol Appl 9:301-319.

Turner CL, Seastedt TR, Dyer ML, Kittel TGF, Schimel DS (1992) Effects of management and topography on the radiometric response of a tallgrass prairie. J Geophys Res Atmos 97:1885518866.

van Bommel FPJ, Heitkonig IMA, Epema GPF, Ringrose S, Bonyongo C, Veenendaal EM (2006) Remotely sensed habitat indicators for predicting distribution of impala (Aepyceros melampus) in the Okavango Delta, Botswana. J Trop Ecol 22:101-110.

Verlinden A, Masogo R (1997) Satellite remote sensing of habitat suitability for ungulates and ostrich in the Kalahari of Botswana. J Arid Environ 35:563-574.

Waller JS, Mace RD (1997) Grizzly bear habitat selection in the Swan Mountains, Montana. J Wildl Manage 61:1032-1039.

Wallin DO, Elliott CCH, Shugart HH, Tucker CJ, Wilhelmi F (1992) Satellite remote sensing of breeding habitat for an African weaverbird. Landsc Ecol 7:87-99.

Wessman CA, Bateson CA, Benning TL (1997) Detecting fire and grazing patterns in tallgrass prairie using spectral mixture analysis. Ecol Appl 7:493-511

Woodcock C, Harward VJ (1992) Nested-hierarchical scene models and image segmentation. Int J Remote Sens 13:3167-3187.

Woodcock CE, Allen R, Anderson M, Belward A, Bindschadler R, Cohen W, Gao F, Goward SN, Helder D, Helmer E et al. (2008) Free access to Landsat imagery. Science 320:1011-1011.

Wulder M (1998) Optical remote-sensing techniques for the assessment of forest inventory and biophysical parameters. Prog Phys Geogr 22:449-476.

Wulder MA, LeDrew EF, Franklin SE, Lavigne MB (1998) Aerial image texture information in the estimation of northern deciduous and mixed wood forest leaf area index (LAI). Remote Sens Environ 64:64-76. 
Wulder MA, Dechka JA, Gillis MA, Luther JE, Hall RJ, Beaudoin A (2003) Operational mapping of the land cover of the forested area of Canada with Landsat data: EOSD land cover program. For Chron 79:1075-1083.

Wulder MA, Hall RJ, Coops NC, Franklin SE (2004) High spatial resolution remotely sensed data for ecosystem characterization. Bioscience 54:511-521.

Yanasse CCF, Sant'Anna SJS, Frery AC, Renno CD, Soares JV, Luckman AK (1997) SIR-C dependence on tropical forest regeneration stages. Remote Sens Environ 59:180-190.

Zimble DA, Evans DL, Carlson GC, Parker RC, Grado SC, Gerard PD (2003) Characterizing vertical forest structure using small-footprint airborne LiDAR. Remote Sens Environ 87:171-182.

Ortega-Huerta MA, Medley KE (1999) Landscape analysis of jaguar (Panthera onca) habitat using sighting records in the Sierra de Tamaulipas, Mexico. Environ Conserv 26(4):257-269.

This is a proof version of the chapter published as cited below:
McDermid, G.J., N.C. Coops, M.A. Wulder, S.E. Franklin, and N.E.
Seitz. 2010. Critical remote sensing contributions to spatial wildlife
ecological knowledge and management. Chapter 11, Pages 193-221, in
S.A Cushman and F. Huettmann (Eds), Spatial Complexity, Informatics
and Wildlife Conservation, Springer/Tokyo-Japan, 458p.
DOI: http://dx.doi.org/10.1007/978-4-431-87771-4_11

